\title{
Software for the calculation of Optimization and Technical-Economical Viability for Pumping Stations with the Integration of Renewable Energies
}

\author{
E. Sainz, J.F.Sanz, M.Sanz and M. Navarro \\ Department of Electrical Engineering, University of Zaragoza \\ CIRCE Foundation \\ C/ María de Luna 3, 50018 Zaragoza (Spain) \\ E.Sainz phone: +34 976762 748, e-mail: esainz@ unizar.es \\ J.F.Sanz phone: +34 976762 403, e-mail: jfsanz@unizar.es \\ M.Sanz phone: +34976 761 925, e-mail: msanz@unizar.es, \\ M. Navarro phone: +34 976762403 , e-mail: mnavarro@unizar.es,
}

\begin{abstract}
.
The wind power energy, in addition to the problem related to its randomness, has the disadvantage which it needs a high electrical infrastructure, what means that wind power generating systems must be made with great number of machines to assure its yield. It is also necessary an important infrastructure in the electrical net, and it is the main reason which explain the bureaucratic disadvantages for connecting the wind turbines to the net. Nevertheless, if it is considered its integration with other systems, sharing part of the infrastructure, its cost of installation diminishes and its yield increases, still with smaller number of machines and equivalent hours. In this paper it's shown a computer science tool that studies the combination of a large pumping station for irrigation with renewable power supports. This tool analyzes the optimal dimensions of all elements of the installation, as well as it considers the economic returns that will be derived from its operation. This study has been done in the area of "Andorra" (Teruel, Spain)
\end{abstract}

\section{Key words}

Integration of Renewable Energy Sources, Pumping Stations, technical-economical viability, calculation tool.

\section{Introduction}

In the last years it has appeared a special preoccupation by the economic and environmental impacts from the production of the energy with the traditional methods (thermal and nuclear production). The renewable resources appear like a possible solution to these impacts, although they entail problems of stability of the provision and evacuation to the electrical network. These problems can be reduced integrating the wind power generating systems in other facilities with which it shares part of the infrastructure. [1].

In these conditions, the operation of the wind turbines can be raised in one double slope: on the one hand, selling energy with a smaller cost of installation; on the other hand, in isolated operation, which eliminates the bureaucratic disadvantages of network connection.

With this mentality, from project FIIER of foundation CIRCE and the Department of Electrical Engineering of the University of Zaragoza, in program ALTENER, it has been analyzed the integration of renewable resources, wind power support and hydroelectric generation in facilities of water pumping for irrigating consumption.

\section{Integration of renewable energies in pumping stations}

The advantage of the renewable resources into the pumping station considers from two slopes. On the one hand, incorporating a wind power support that generates electricity for self-consumption of the pumps, reducing or eliminating the consumption of these from the electrical net, accumulating the water in a regulation raft. This is a solution that gives exit to a possible potential of the wind and it faces the difficulties at the same time that nowadays exist for implanting wind power generating centers for energy sale. On the other hand, if the wind potential is elevated and, after supplying energy to the pumping for irrigation, even it is excessive power, the water pumping continues for other utility, not for consumption. This excess of water will produce electricity by incorporating a hydroelectric power station [4]. And the crop would be destined for a biomass generating central [3].

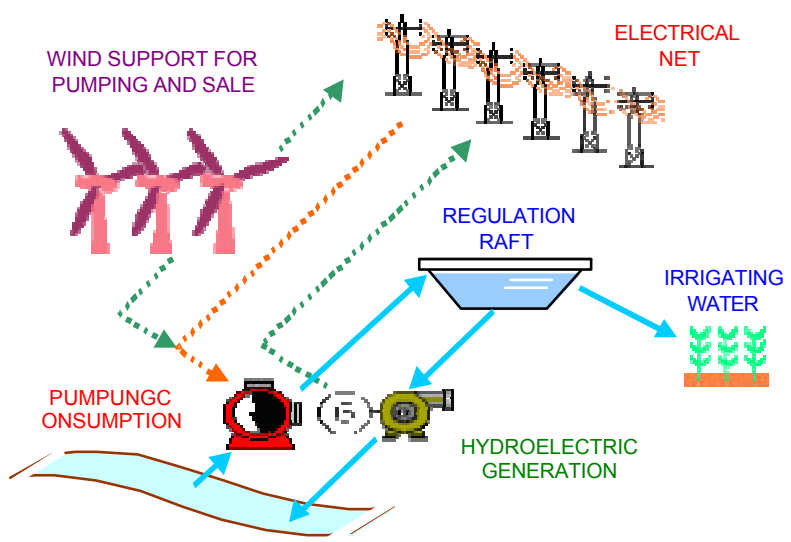

Fig. 1. Pumping system with integration of renewable energies.

This proposal also presents a way of improving the development of sources in rural areas [2].

\section{Previous works}

Within project FIIER in University of Zaragoza and CIRCE Foundation, applications for the calculation of the costs of investment of this type of facilities (program CCIBER) and for the optimization of the operation of the same ones have been developed, looking for so large of raft and volumes of pumping economically (program HIIER). For the optimization of the facilities, a detailed study is applied, throughout the more than 8000 hours of 
the year, of the times of pumping, electrical consumption, water levels in raft, and so on, looking for to diminish the network consumption, in special in the most expensive hours of the day. It has been developed computer science tools on Excel and Visual BASIC.

\section{OEBIER computer science tool}

\section{A. Main characteristics}

A new developed tool, with the name of OEBIER (Optimización de Estaciones de Bombeo con Integración de Energías Renovables), joins and improves the optimizations and studies that carried out programs CCIBER and HIIER, allowing simultaneously to consider the costs of investment necessary to incorporate the advantage of the renewable resources, and to analyse operation cost, with expenses by consumption from the electrical net, maintenance and insurance, and with income by sale of the generated energy. It enlarges the possibilities about optimization, looking for, in addition as large as raft and power to pumping, the more suitable number and type of pumps, wind turbines and hydroelectric turbine. It allows to select the modality of purchase and sale of the electrical energy, and in the case of the network consumption it allows to optimize the power contracted to the electrical company.

The tool makes a double optimization. On one hand, make the necessary calculations in order to find the best technical characteristics of the involved system (pumping, wind and hydroelectric generation). On the other hand, also tries to take advantage of the renewable resources in the most efficient way. Both kind of optimizations search the solution with the most appropriate economical result.

The renewable integration options of the OEBIER program are the following ones:

1) Simple water pumping: it is possible to analyse the case of the simple pumping system, without any kind of renewable resource, in order to make comparisons for studying the reduction improved with the renewable supports, or simply for analysing the economical viability of the pumping station.

2) Water pumping with wind support: It consists of the use of wind energy power (obtained by means of a meteorological study) in order to reduce the consumption of the pumping system. The program allows the user to specify if the free wind power which has not been used for the pumping support can be sold in the electrical market.

3) Pumping with hydroelectric generation: With the installation of original pumping, it is used the dam like energy reserve, so the pumps also works elevating extra water (additional to the consumption necessities) in order to generate hydroelectric energy later with this water.

4) Full renewable use: Is the most complete case analysed by OEBIER, in which the both previous options are combined. The wind power support reduces the cost of electrical consumption of the pumping system, both for elevating necessary water for direct use and water used for future hidroelectric generation.

Tool OEBIER has been programmed in $\mathrm{C}$ and Java languages, with the use of free software. This also allows its free use, with no need of any type of license.

\section{B. Necessary information}

In order to make a complete study and optimization of a pumping system with renewable supports, it is necessary to specify four kind of input data:

- General specifications of the pumping necessities

- Technical data of the involved systems (pumping, wind and hydroelectric generation)

- Water necessities

- Economical factors for the viability analysis

The general specifications are related to the kind of renewable support, the length of the pipe, the pumping high, and some technical information about the electrical net for energy supply.

The program allows to calculate the geometric height of impulsion and the length of the impulsion pipe, from UTM coordinates of the main vertexes of the pipe profile. Its diameter will be calculated of optimal way, according to the most convenient pumping power.

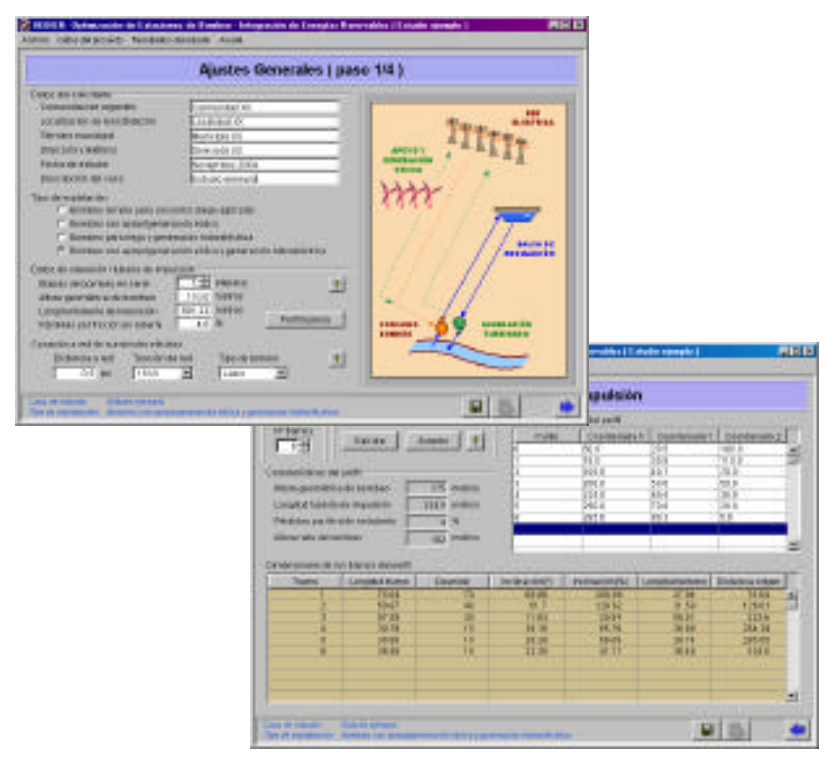

Fig. 2. Configuration of general specifications.

Technical data are needed to be specify, in order to determine what parameters must be optimized, what are the optimization margins, or what are the values of fixed parameters.

In this point, is necessary to establish the optimzation margin or fixed value for:

- The pumping power and the dam water capacity

- The number and kind of pumps

- The number and kind of wind turbines

- The kind of hydroelectric turbine

In addition to this, in order to make a preliminary wind power study, it is also necessary to define some geographical and meteorological information. 


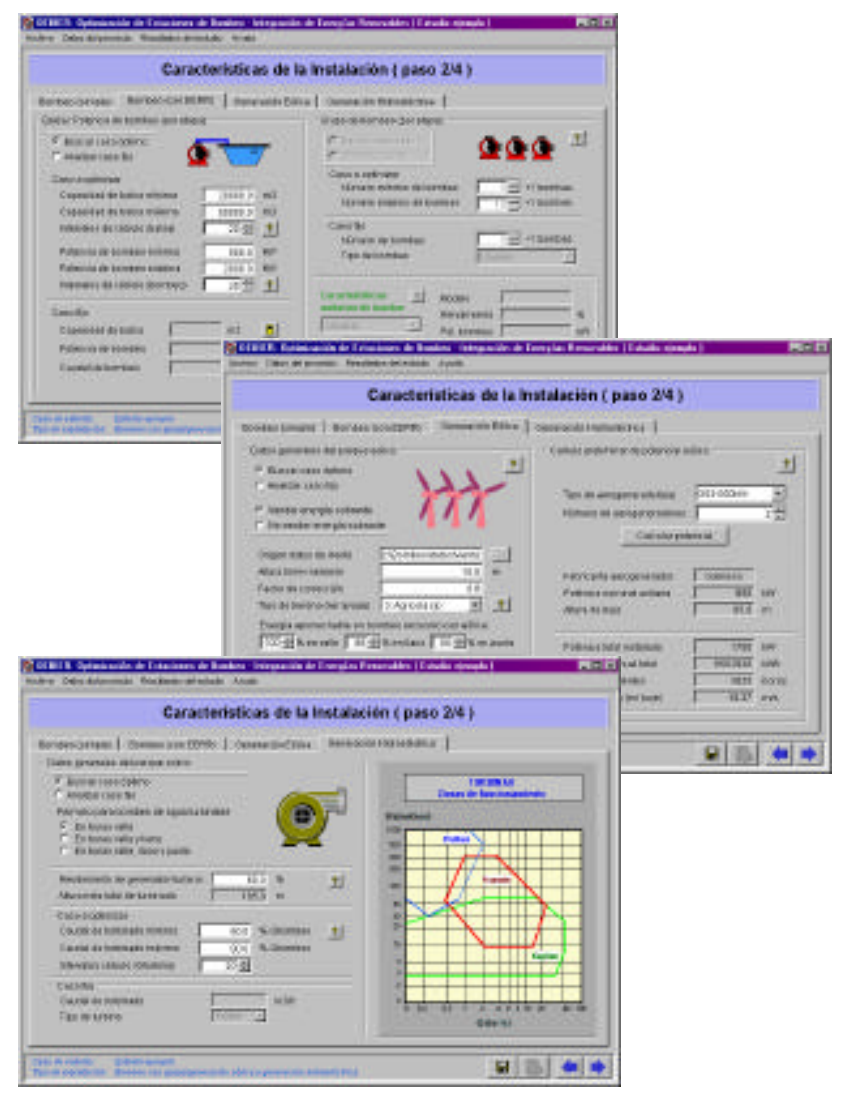

Fig. 3. Configuration of pumping facilities, wind power and hydroelectric.

Tool OEBIER needs to know the necessities of water for irrigation. If the application is used to analyse a pumping system in a zone which belongs to the Spanish region of Aragón, it is able to leave the program automatically calculate these necessities based on the type of crop and its extension. It is possible to describe the daily distribution of the irrigation, to establish minimum levels of reserve in the regulation raft, and to define water limitations by concession of irrigation.

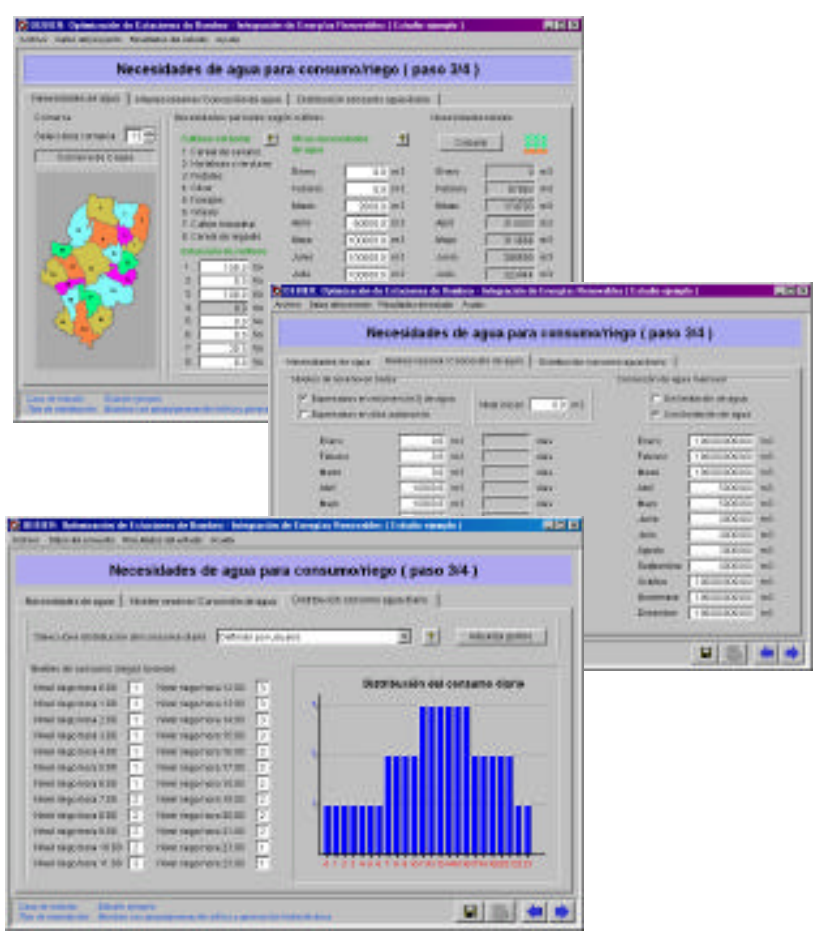

Fig. 4. Configuration of water consumption necessities.
The application allows us to fit the modality of purchase and sale of the electricity. It is possible to be selected to anyone of the existing tariffs of purchase or the access to the electrical liberalised market. Dealing with the electrical sale of generated energy, it is possible to be defined if you want to access to the free trade (with the additional accounts which increments the trade price), or selling with a fixed price.

It is also necessary to establish values for evaluating the economic viability, such as the percentage of own resources, other people's and subventions for the investment, interest of the loan, rate of inflation, percentage of annual increase for the prices of purchase and sale of the electricity, and so on.

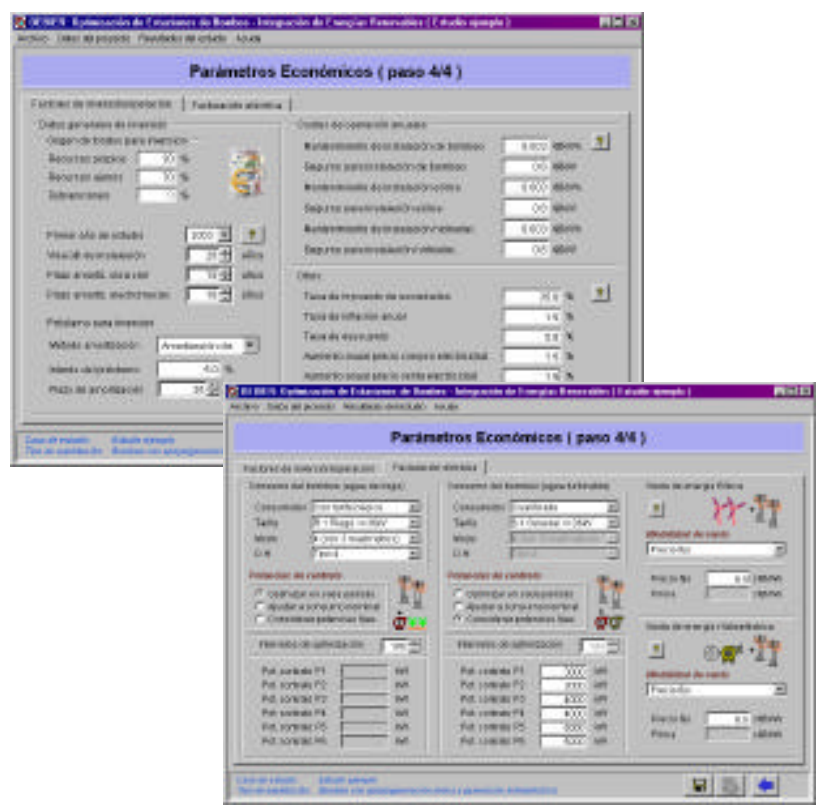

Fig. 5. Configuration of economical data

\section{Optimized variables}

Program OEBIER allows to optimize simultaneously the pumping power of the impulsion system and the size of the regulation raft, looking for the case that better result shows in some of the economic rates. The user can choose the economic criterion for the optimization, with the parameter of NPV (Net Present Value), IRR (Internal Rate of Return), PB (Pay Back) or Rentability.

According to the optimal power that finds the application, it calculates the diameter of the impulsion pipe. After that, it automatically looks for the more interesting number and model of pumps. The tool has a data base with characteristics of commercial pumps of different manufacturers (Caprari, Ebara, Omega-Itur, Hidrotecar), in order to make the optimal search.

Contributing the wind data, corresponding to the average speed in each one of the hours of the year, tool OEBIER applies the power curve of a wind turbin to determine the wind potential. It uses the equation of the velocity profile of the wind to adapt the measurements to the height of the wing turbine. It allows to apply a correction factor to 
apply a more or less pessimistic criterion on the waited for wind potential. The application has a data base with the curves of powers of different models from commercial wind turbines, of different manufacturers (Gamesa, Neg-Micon, Nordex, Vestas, Südwind). The program estimates, with each model and for different number of machines, the economic result, and it gives back the optimal case.

It determines the most suitable proportions of the beginning from the considered efficiency of the group which forms the electrical generator and hydraulic turbine. It allows to decide in what hours of the days to be able to elevate water connecting the pumps to the electrical net, according to which the cost of the consumption is more or less expensive.

If the installation does not allow a total self-consumption with the wind power, it allows to calculate the most suitable value of the power contracted to the electrical company in each one of the periods of consumption (valley, level and pick hours).

If some of the commented parameters, susceptible of optimization, must be fixed by the premises of the study, it is possible not to optimize and to fit as it is desired.

\section{Results of the optimization study}

Program OEBIER, after the calculations of optimization, informs into the characteristics (dimensions, powers, and so on) of the optimized system.

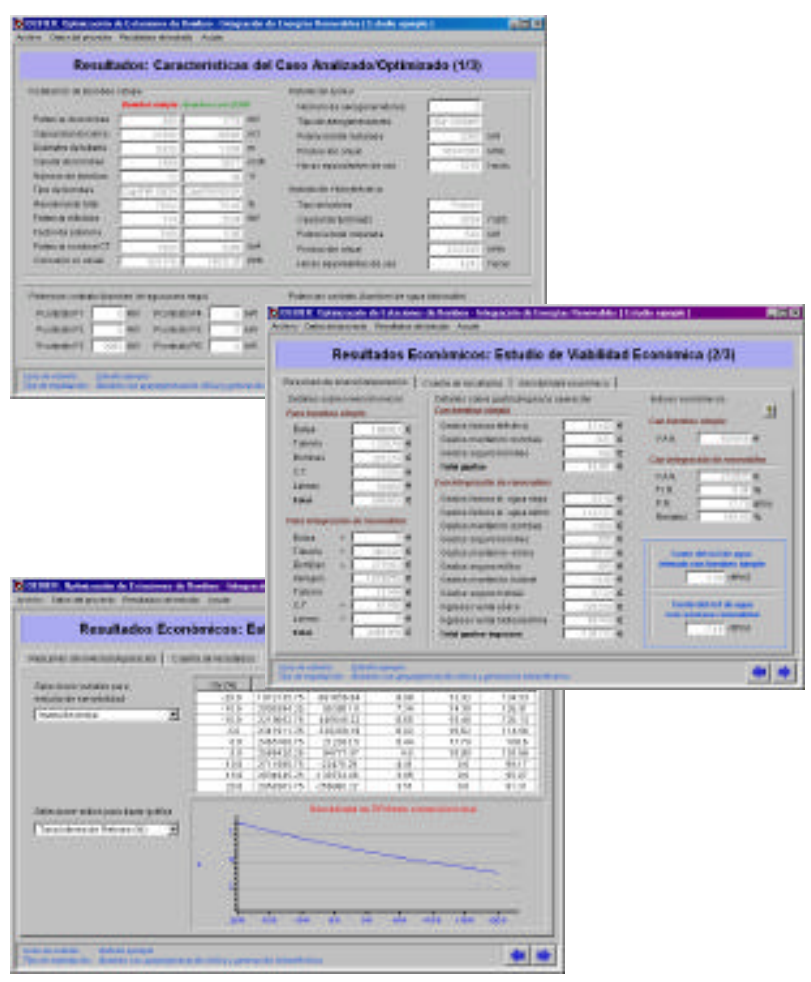

Fig. 6. Results of a optimized system.

It also shows the results related to:

- The costs of investment of each part of the pumping system with renewable supports
- The costs of operation by electricity consumption, and income by sale

- The account of economical results for the optimized project

- The sensitivity of the economic rates (NPV, IRR, PB and Rentability) as opposed to variations of the investment, expenses or income, inflation, etc.

In addition to the economic results which are necessary to analyse the economic viability, application OEBIER also shows the monthly characteristics of operation in the first year of use, on consumed and generated energy, expenses and income, elevated volume of water (for consumption or hydroelectric generation), and so on.

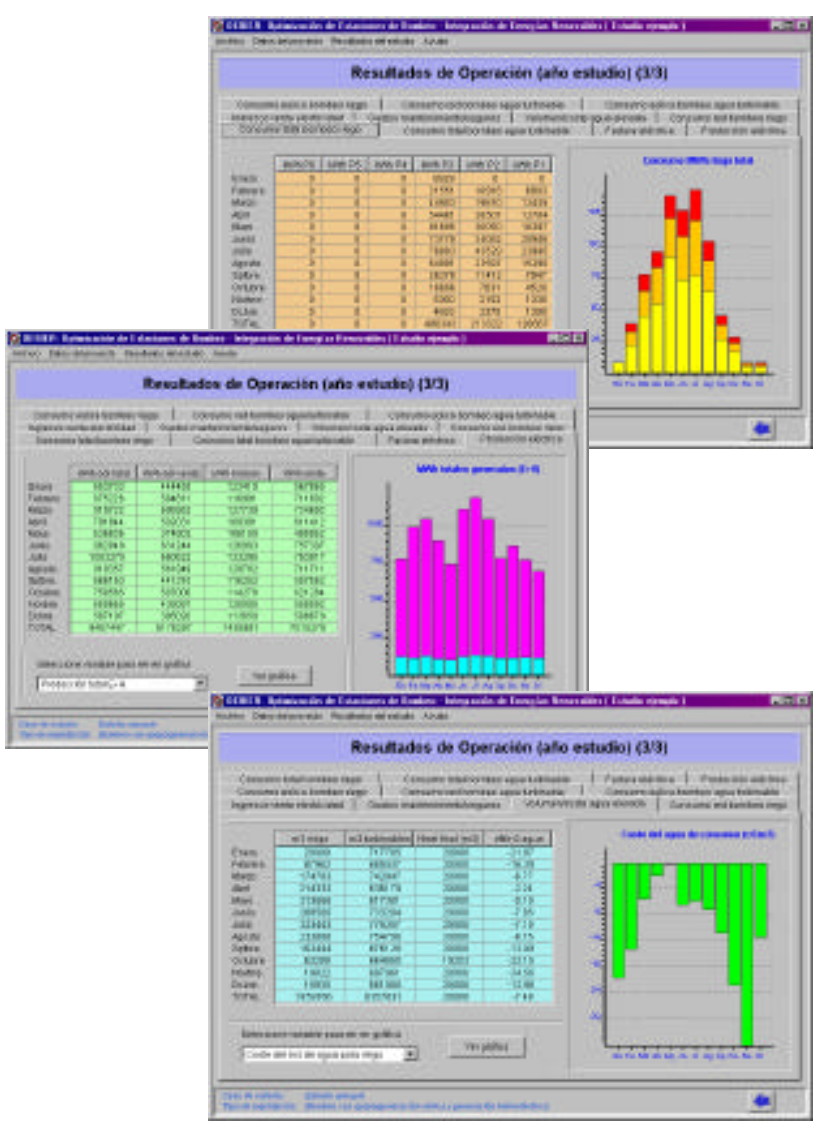

Fig. 7. Results of operation of theoptimized system.

All the numerical results about the optimization process and the optimal project are kept by tool OEBIER in files with text format, so that they can be opened by applications standard. In this way, the data can be used to generate information or to apply other mathematical calculations, extending the made ones by tool OEBIER.

\section{Application of the tool in a real study}

\section{A. Characteristics of the installation}

A great pumping station, in the area of Andorra (Teruel, Spain) is been analyzed in order to determine the economical viability of the wind power support.

The installation general map can be seen on the figure bellow. The elevation is made in four steps, with two intermediate water extractions, three different dams 
which accumulate the water demanded in different areas. and wind power support in all the pumping steps.

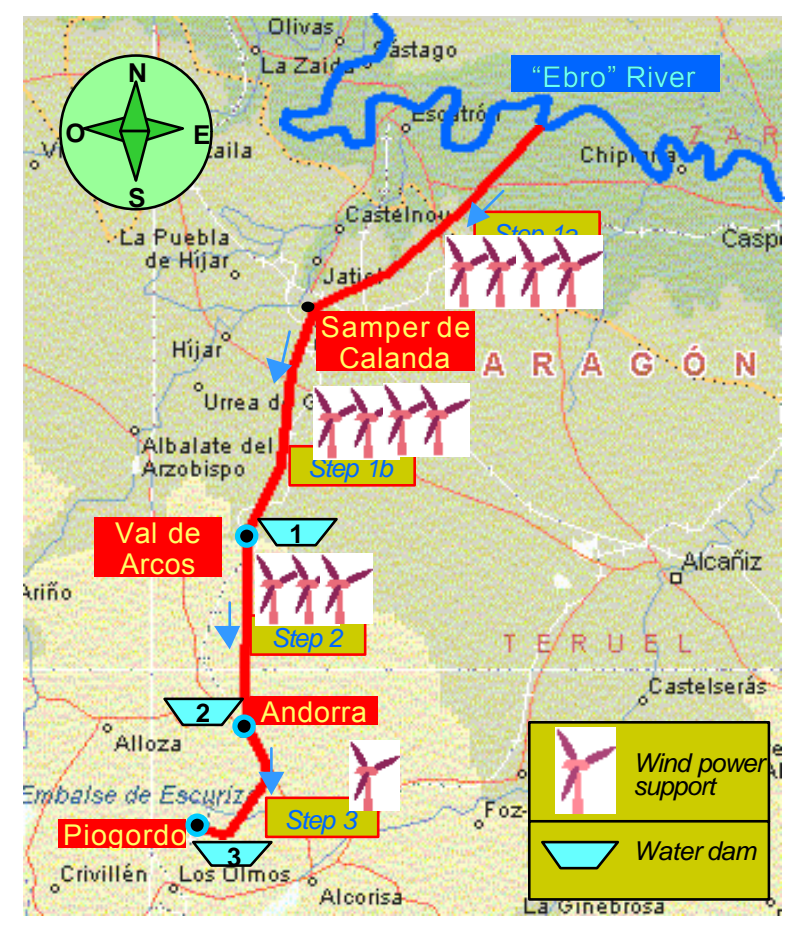

Fig. 8. General map of the pumping stations

The monthly water demand is known (for irrigating, domestic and industrial use) in each one of the zones, so that they take to the following pumping necessities:

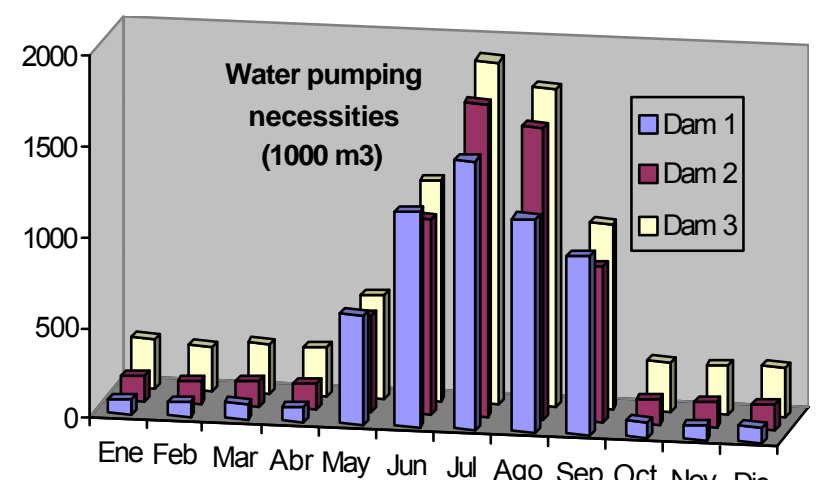

Fig. 9. Water pumping necessities $\left(10^{3} \mathrm{~m}^{3}\right)$.

This pumping system has been initially projected with the technical characteristics that appear in table I.

TABLE I. -Technical data about the pumping station.

\begin{tabular}{||l||c|c|c|c||}
\hline & Step 1a & Step 1b & Step 2 & Step 3 \\
\hline \hline $\begin{array}{l}\text { Pumping } \\
\text { height }\end{array}$ & $215 \mathrm{~m}$ & $230 \mathrm{~m}$ & $170 \mathrm{~m}$ & $40 \mathrm{~m}$ \\
\hline \begin{tabular}{l} 
Pipe length \\
\hline $\begin{array}{l}\text { Pumping } \\
\text { volume }\end{array}$
\end{tabular} & $20,6 \mathrm{~km}$ & $13,9 \mathrm{~km}$ & $7,8 \mathrm{~km}$ & $3,8 \mathrm{~km}$ \\
\hline Dam size & - & $1,91 \mathrm{~m}^{3} / \mathrm{s}$ & $1,36 \mathrm{~m}^{3} / \mathrm{s}$ & $0,72 \mathrm{~m}^{3} / \mathrm{s}$ \\
\hline $\begin{array}{l}\text { Wind power } \\
\text { support }\end{array}$ & $4 \times 650 \mathrm{~kW}$ & $4 \times 650 \mathrm{~kW}$ & $3 \times 650 \mathrm{~kW}$ & $1 \times 650 \mathrm{~kW}$ \\
\hline \hline
\end{tabular}

For this initial proposal, it has been considered a total efficiency of $70 \%$ in the pumping process, and a wind support with Vestas turbins (V47-650 model).

In order to obtain economical results, related not only with the necessary investment but also with the costs of the electrical consumption, maintenance and insurance of the system, the following rates have been taken into account:

$\begin{array}{lll}\text { - Useful life: } & 20 \text { years } \\ \text { - } & \text { Own / outer resources: } & 35 \% / 65 \% \\ \text { - } & \text { Inflation / taxes: } & 1,5 \% / 35 \% \\ \text { - } & \text { Loan rate / updating rate: } & 3 \% / 3 \% \\ \text { - } & \text { Electric contract: } & 2.1 \text { High Voltage }(\leq 36 \mathrm{kV}) \\ \text { - } & \text { Without electric energy sale }\end{array}$

\section{B. Summary of results: initial proposal}

With the use of OEBIER tool it has been analysed the viability of the pumping system, for each one of the pumping steps, and with the technical characteristics shown in the table above. In order to know the convenience of installing the wind power support, the tool makes a comparison between the cost with or without this renewable energy, as shown in table II. The consumption reductions owing to the wind support are also presented in percentages.

TABLE II. - Consumption results for the initial proposal.

\begin{tabular}{|c|c|c|c|}
\hline \multicolumn{4}{|c|}{ Simple pumping (without renewable wind support) } \\
\hline & Step 1 & Step 2 & Step 3 \\
\hline $\begin{array}{l}\text { Power } \\
\text { consumption }\end{array}$ & $38,5 \mathrm{GWh}$ & $10,47 \mathrm{GWh}$ & $1,36 \mathrm{GWh}$ \\
\hline Electric cost & $2670 \cdot 10^{3} €$ & $735 \cdot 10^{3} €$ & $92,4 \cdot 10^{3} €$ \\
\hline Water cost & $12,7 \mathrm{c} € / \mathrm{m}^{3}$ & $4,9 \mathrm{c} € / \mathrm{m}^{3}$ & $1,12 \mathrm{c} € / \mathrm{m}^{3}$ \\
\hline \multicolumn{4}{|c|}{ Pumping with renewable wind support } \\
\hline & Step 1 & Step 2 & Step 3 \\
\hline $\begin{array}{l}\text { Power } \\
\text { consumption }\end{array}$ & $\begin{array}{l}29,3 \mathrm{GWh} \\
(-23,82 \%)\end{array}$ & $\begin{array}{c}7,125 \mathrm{GWh} \\
(-32 \%)\end{array}$ & $\begin{array}{c}0,36 \mathrm{GWh} \\
(-73,5 \%)\end{array}$ \\
\hline Electric cost & $\begin{array}{c}2160 \cdot 10^{3} € \\
(-19,1 \%)\end{array}$ & $\begin{array}{l}556 \cdot 10^{3} € \\
(-24,3 \%)\end{array}$ & $\begin{array}{l}34,8 \cdot 10^{3} € \\
(-62,3 \%)\end{array}$ \\
\hline Water cost & $\begin{array}{c}10,35 \mathrm{c} € / \mathrm{m}^{3} \\
(-18,5 \%) \\
\end{array}$ & $\begin{array}{c}3,74 \mathrm{c€} / \mathrm{m}^{3} \\
(-23,7 \%) \\
\end{array}$ & $\begin{array}{c}0,43 \mathrm{c} € / \mathrm{m}^{3} \\
(-61,6 \%)\end{array}$ \\
\hline
\end{tabular}

As an example, the graphics bellow shows a comparison between the monthly energy consumption and the monthly water medium cost along one complete year, for the first pumping step in the initial proposal.

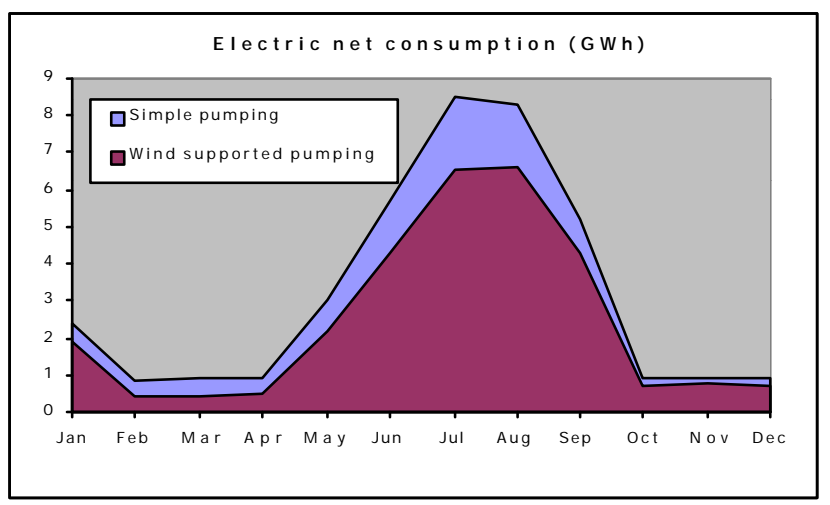

Fig. 10. Consumption from the electric net (initial proposal). 
Taking into account additional costs for the investment (in wind turbines) maintenance and insurance (apart from the electric annual cost shown in the table), the result related with the main economical rates are ones in the following table.

TABLE III. - Economic results for the initial proposal.

\begin{tabular}{||l|c|c|c||}
\hline \multicolumn{4}{|c||}{ Pumping with renewable wind support } \\
\hline & Step 1 & Step 2 & Step 3 \\
\hline Investment & $4,8 \cdot 10^{6} €$ & $1,8 \cdot 10^{6} €$ & $0,6 \cdot 10^{6} €$ \\
\hline Pay Back & 15,22 years & 16,26 years & 18,66 years \\
\hline N.P.V. & $1,35 \cdot 10^{6} €$ & $0,36 \cdot 10^{6} €$ & $0,34 \cdot 10^{6} €$ \\
\hline I.R.R. & $5,65 \%$ & $4,93 \%$ & $3,59 \%$ \\
\hline
\end{tabular}

The annual cash flows for the calculation of the pay back, the NPV and the IRR have been obtained from the saving in the electric cost of net consumption, thanks to the wind support.

We can see that the renewable support is economically convenient for all the pumping steps. Any way, the economic viability is better in the first step than in the last one, owing to the important energetic necessities at the beginning of the pumping process (with a higher pumping heigth).

\section{Summary of results: optimized proposal}

Thanks to the optimization capabilities of the OEBIER tool, it has been search the technical characteristics of the pumping system, in each one of the pumping steps, for obtaining the best economic result, with the following results:

TABLE IV. - Technical data of the optimized pumpimg station.

\begin{tabular}{||l||c|c|c||}
\hline & Step 1 & Step 2 & Step 3 \\
\hline \hline $\begin{array}{l}\text { Pumping } \\
\text { volume }\end{array}$ & $1,77 \mathrm{~m}^{3} / \mathrm{s}$ & $1,44 \mathrm{~m}^{3} / \mathrm{s}$ & $0,722 \mathrm{~m}^{3} / \mathrm{s}$ \\
\hline Dam size & $1365 \cdot 10^{3} \mathrm{~m}^{3}$ & $195 \cdot 10^{3} \mathrm{~m}^{3}$ & $300 \cdot 10^{3} \mathrm{~m}^{3}$ \\
\hline $\begin{array}{l}\text { Wind power } \\
\text { support }\end{array}$ & $\begin{array}{c}3 \times 1000 \mathrm{~kW} \\
\text { (Nordex N54) }\end{array}$ & $\begin{array}{c}2 \times 1000 \mathrm{~kW} \\
\text { (Nordex N54) }\end{array}$ & $\begin{array}{c}1 \times 600 \mathrm{~kW} \\
\text { (Nordex N43) }\end{array}$ \\
\hline
\end{tabular}

The most significant difference between the initial and the optimized proposal is the size of the dam at the end of the first pumping step. Owing to the important pumping height for the first step, it is recommended the increasing of its dam in order to reduce the electric energy consumption at pick hours. The optimized total power of the wind support is similar to the initial case.

As in the previous analysis for the initial proposal, in order to know the convenience of installing the wind power support, the tool makes a comparison between the cost with or without this renewable energy, as shown in table V.
TABLE V. - Consumption results for the optimized proposal.

\begin{tabular}{||l|c|c|c||}
\hline \hline \multicolumn{5}{||c||}{ Optimized simple pumping (without renewable wind support) } \\
\hline & Step 1 & Step 2 & Step 3 \\
\hline $\begin{array}{l}\text { Power } \\
\text { consumption }\end{array}$ & $32,68 \mathrm{GWh}$ & $8,8 \mathrm{GWh}$ & $1,19 \mathrm{GWh}$ \\
\hline Electric cost & $2130 \cdot 10^{3} €$ & $605 \cdot 10^{3} €$ & $83,4 \cdot 10^{3} €$ \\
\hline Water cost & $10,15 \mathrm{c} € / \mathrm{m}^{3}$ & $4,03 \mathrm{c} € / \mathrm{m}^{3}$ & $1,01 \mathrm{c} € / \mathrm{m}^{3}$ \\
\hline \hline \multicolumn{4}{|c||}{ Optimized pumping with renewable wind support } \\
\hline \multicolumn{1}{|c|}{\begin{tabular}{|c|c|c||} 
Step 1 \\
consumption
\end{tabular}} & $\begin{array}{c}25,8 \mathrm{GWh} \\
(-21 \%)\end{array}$ & $\begin{array}{c}4,65 \mathrm{GWh} \\
(-47,22 \%)\end{array}$ & $\begin{array}{c}0,34 \mathrm{GWh} \\
(-80,6 \%)\end{array}$ \\
\hline Electric cost & $\begin{array}{c}1670 \cdot 10^{3} € \\
(-21,6 \%)\end{array}$ & $\begin{array}{c}386,6 \cdot 10^{3} € \\
(-36 \%)\end{array}$ & $\begin{array}{c}33,42 \cdot 10^{3} € \\
(-60 \%)\end{array}$ \\
\hline Water cost & $\begin{array}{c}7,97 \mathrm{c} € / \mathrm{m}^{3} \\
(-21,48 \%)\end{array}$ & $\begin{array}{c}2,55 \mathrm{c} € / \mathrm{m}^{3} \\
(-36,7 \%)\end{array}$ & $\begin{array}{c}0,41 \mathrm{c} € / \mathrm{m}^{3} \\
(-59,4 \%)\end{array}$ \\
\hline
\end{tabular}

As an example, the graphics bellow shows a comparison between the monthly energy consumption and the monthly water medium cost along one complete year, for the first pumping step in the optimized proposal.

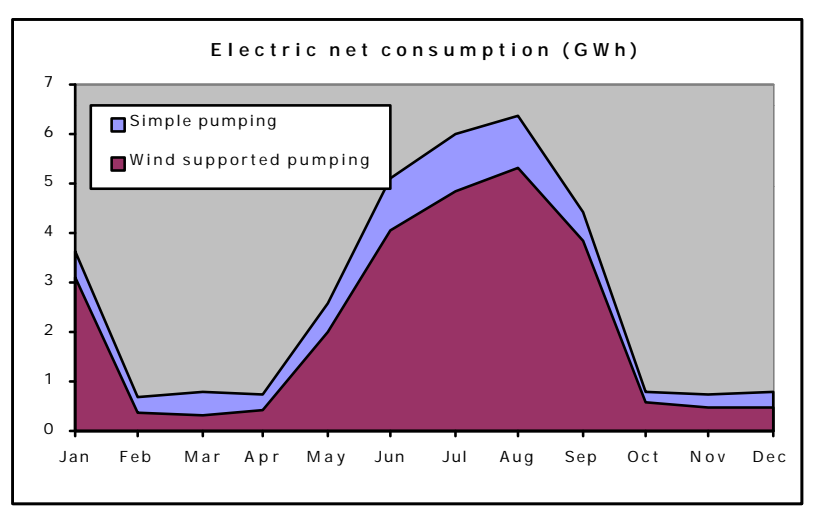

Fig. 11. Consumption from the electric net (optimized proposal).

Taking into account additional costs for the investment (in wind turbines) maintenance and insurance (apart from the electric annual cost shown in the table), the result related with the main economical rates are the ones in the following table.

TABLE VI. - Economic results for the optimized proposal.

\begin{tabular}{||l|c|c|c||}
\hline \hline \multicolumn{4}{|c||}{ Pumping with renewable wind support } \\
\hline & Step 1 & Step 2 & Step 3 \\
\hline Investment & $2,57 \cdot 10^{6} €$ & $1,71 \cdot 10^{6} €$ & $0,52 \cdot 10^{6} €$ \\
\hline Pay Back & 8,79 years & 13,14 years & 18,41 years \\
\hline N.P.V. & $2,87 \cdot 10^{6} €$ & $0,74 \cdot 10^{6} €$ & $0,035 \cdot 10^{6} €$ \\
\hline I.R.R. & $12,3 \%$ & $7,06 \%$ & $3,71 \%$ \\
\hline
\end{tabular}

We can see that the renewable support for this optimized system is also economically convenient for all the pumping steps. And, in comparison with the initial proposal, appears an economic improvement; the pay backs are lower, that is, the NPV and IRR are higher than for the initial case. 


\section{Conclusions}

With this integrating proposal, it is presented an exit for renewable resources, simple and reliable, that gives solution to problems of electrical unloading to network, with the self-consumption.

It appears, with OEBIER, a computer science tool that allows to study, on a fast way, the economic viability of the integration of the renewable resources in facilities of pumping for irrigation. A separated or integrated study of the wind support and the hydroelectric generation is allowed, having a computer interface easy to handle, with an interesting versatility and speed of optimization. And it offers varied information and in different formats, with tables and graphics simple to be interpreted.

With different analysis made with the OEBIER tool, we get to the clear conclusion of the economic viability of the wind support, not as much in the hydroelectric resource due to the low efficiency of this one mixed with the pumping process efficiency.

\section{References}

[1] José Sanz Osorio, Diego Botero, Mariano Sanz. (2001) "Integración de Energías Renovables en Instalaciones de Bombeo para Riego. Proyecto FIIER", $7^{a s}$ Jornadas Hispano Lusas de Ingeniería Eléctrica, Vol., $3^{\circ}$, pp 371.

[2] Kilias V., Nikopoulos P. Choudalis P. Papadopoulus A. Zafiris CH 2000 "Development of a computerized Information Tool to Increase the Penetration of Renewable Energy Sources in Agricultural Sector", Altener 2000 Conference, pp 255-258

[3] J.P Antoine, E.Stubbe, A. Van Ranst, y otros 2001 "IRENE 2010: Integration of the Renewable Energy in the Electrical Network", Altener 2000 Conference.

[4] D. Diakoulaki, G. Caralis, A. Zervos, (2001) "Strategies for Communities Aiming at 100\% RES Supply", Altener 2000 Conference, pp 158.

[5] IDAE, IPTS, EUFORES, ETSU, FFZ y otros 2000 "The ENER-IURE Project Phase II: Technical Recommendations of five Areas: Fiscal, Subsidies, Planning, Agriculture and Electricity", Altener 2000 Conference, pp 217- 219 